\title{
Activity-Dependent Development of Calcium Regulation in Growing Motor Axons
}

\author{
Gregory A. Lnenicka, Kathleen F. Arcaro, and John M. Calabro \\ Neurobiology Research Center, Department of Biological Sciences, University at Albany, State University of New York, \\ Albany, New York 12222
}

In cultured nerve cord explants from the crayfish (Procambarus clarkii), the normal impulse activity levels of growing motor axons determine their response to $\mathrm{Ca}^{2+}$ influx. During depolarization or $\mathrm{Ca}^{2+}$ ionophore application, normally active tonic motor axons continue to grow, whereas inactive phasic motor axons retract and often degenerate. To determine the role of $\mathrm{Ca}^{2+}$ regulation in this difference, we measured the intracellular free $\mathrm{Ca}^{2+}$ concentration $\left(\left[\mathrm{Ca}^{2+}\right]_{\mathrm{i}}\right)$ with fura-2. Growth cones from tonic axons normally had a higher $\left[\mathrm{Ca}^{2+}\right]_{i}$ than those from phasic axons. When depolarized with $60 \mathrm{~mm} \mathrm{~K}^{+}$, growth cones and neurites from phasic axons had a $\left[\mathrm{Ca}^{2+}\right]_{i}$ three to four times higher than did those from tonic axons. This difference in $\mathrm{Ca}^{2+}$ regulation includes greater $\mathrm{Ca}^{2+}$-handling capacity for growing tonic axons; the increase in $\left[\mathrm{Ca}^{2+}\right]_{\mathrm{i}}$ produced by the

Intracellular $\mathrm{Ca}^{2+}$ is important in the control of many neuronal processes, such as transmitter release (Katz, 1969), membrane excitability (Turrigiano et al., 1994), gene transcription (Morgan and Curran, 1991), and neuron growth (Kater and Mills, 1991) and survival (Nishi and Berg, 1981). The regulation of intracellular free $\mathrm{Ca}^{2+}$ concentration $\left(\left[\mathrm{Ca}^{2+}\right]_{\mathrm{i}}\right)$ involves a number of processes, including influx through membrane channels, release from intracellular stores, chelation by $\mathrm{Ca}^{2+}$-binding proteins, uptake into organelles, and extrusion across the plasma membrane. The development and modulation of the mechanisms involved in $\mathrm{Ca}^{2+}$ regulation are of considerable interest, because they are likely to influence the developmental fate of a neuron and its subsequent function.

Studies of crayfish motor axons growing in cell culture suggest that the development of differences in $\mathrm{Ca}^{2+}$ regulation are related to the level of impulse activity. Depolarization inhibits the growth of normally inactive phasic motor axons, eventually producing retraction and often degeneration, whereas growing tonic motor axons normally continue to advance during depolarization (Arcaro and Lnenicka, 1997). These different responses to depolarization are dependent on $\mathrm{Ca}^{2+}$ influx. It appears likely that depolarization results in higher $\left[\mathrm{Ca}^{2+}\right]_{i}$ in phasic axons than in tonic axons, because high levels of intracellular $\mathrm{Ca}^{2+}$ can trigger neurite retraction and degeneration (Cohan et al., 1987; Silver et al., 1989; Mills and Kater, 1990). Differences in $\left[\mathrm{Ca}^{2+}\right]_{\mathrm{i}}$ could

Received Feb. 13, 1998; revised April 6, 1998; accepted April 9, 1998.

This work was supported by National Science Foundation Grant IBN-9511558 (G.A.L.). We thank Drs. John Schmidt and Su Tieman for reviewing this manuscript.

Correspondence should be addressed to Gregory A. Lnenicka, Neurobiology Research Center, Department of Biological Sciences, University at Albany, State University of New York, Albany, NY 12222.

Copyright (ㄷ) 1998 Society for Neuroscience $0270-6474 / 98 / 184966-07 \$ 05.00 / 0$
$\mathrm{Ca}^{2+}$ ionophore 4-bromo-A23187 (0.25 $\left.\mu \mathrm{M}\right)$ is four to five times greater in phasic than in tonic axons, and the decline in $\left[\mathrm{Ca}^{2+}\right]_{i}$ at the end of a depolarizing pulse is three to four times faster in tonic axons than phasic ones. Blocking impulses in growing tonic axons for 2-3 d with tetrodotoxin reduces their capacity to regulate $\left[\mathrm{Ca}^{2+}\right]_{\mathrm{i}}$. Thus, growing tonic and phasic axons have differences in $\mathrm{Ca}^{2+}$ regulation that develop as a result of their different activity levels. These activity-dependent differences in $\mathrm{Ca}^{2+}$ regulation influence axon growth and degeneration and probably influence other neuronal processes that are mediated by changes in $\left[\mathrm{Ca}^{2+}\right]_{\mathrm{i}}$.

Key words: calcium regulation; activity-dependent; fura-2; cell culture; growth cones; crayfish result from a lower $\mathrm{Ca}^{2+}$ current density in growing tonic axons, because increased impulse activity produces a reduction in voltage-dependent $\mathrm{Ca}^{2+}$ currents in crayfish motoneurons (Hong and Lnenicka, 1995, 1997). An additional possibility is that the tonic axons have greater $\mathrm{Ca}^{2+}$-handling capacity, because application of a $\mathrm{Ca}^{2+}$ ionophore also produces greater inhibition of growing tonic axons than phasic axons (Arcaro and Lnenicka, 1997).

In previous studies, differences in $\mathrm{Ca}^{2+}$ regulation have been shown to influence neuronal growth and survival. Cultured $\mathrm{He}$ lisoma neurons with weak $\mathrm{Ca}^{2+}$ regulation show greater neurite retraction and degeneration during $\mathrm{Ca}^{2+}$ influx than those with stronger $\mathrm{Ca}^{2+}$ regulation (Mills and Kater, 1990). There is a positive correlation between the presence of $\mathrm{Ca}^{2+}$-binding proteins and resistance to excitotoxicity in cultures of rat hippocampal and cortical neurons (Mattson et al., 1991; Lukas and Jones, 1994). In cultured hippocampal neurons, increases in $\mathrm{Ca}^{2+}$ channel density are correlated with decreased neuronal survival (Porter et al., 1997).

To examine the relationship between impulse activity and the development of $\mathrm{Ca}^{2+}$ regulation, we have examined the increase in $\left[\mathrm{Ca}^{2+}\right]_{\mathrm{i}}$ produced by high- $\mathrm{K}^{+}$solutions and $\mathrm{Ca}^{2+}$ ionophores in the growth cones and neurites from phasic and tonic axons. Our results show that during prolonged depolarization $\left[\mathrm{Ca}^{2+}\right]_{i}$ goes much higher in growing phasic axons than in tonic axons. This difference in $\mathrm{Ca}^{2+}$ regulation involves greater $\mathrm{Ca}^{2+}$ handling capacity for tonic axons than for phasic axons. The development of these differences in $\mathrm{Ca}^{2+}$ regulation are activitydependent, because eliminating impulse activity in growing tonic axons reduces their $\mathrm{Ca}^{2+}$-handling capacity. The implications of these activity-dependent changes in $\mathrm{Ca}^{2+}$ regulation for the growing axon are discussed. 


\section{MATERIALS AND METHODS}

Preparation of cultures. Nerve cord explant cultures were prepared from crayfish (Procambarus clarkii), which were obtained from Atchafalaya Biological Supply (Raceland, LA), and maintained at $20^{\circ} \mathrm{C}$ in shallow, aerated tanks. Abdominal nerve cords were removed from crayfish with carapace lengths of $1.5-2.5 \mathrm{~cm}$ and plated in defined culture medium, as described previously (Arcaro and Lnenicka, 1995). Briefly, the nerve cord was plated on a coverslip with the deep and superficial third roots arranged such that growth from the phasic and tonic motor axons was easily distinguished. The culture medium consisted of L-15 Medium Leibovitz (1-4386; Sigma, St. Louis, MO) that was diluted 1:1 and contained (in mM): $13.5 \mathrm{CaCl}_{2}, 2.6 \mathrm{MgCl}_{2}, 5.4 \mathrm{KCl}, 206.0 \mathrm{NaCl}, 5.6$ D-glucose, and $10 \mathrm{Na}$-HEPES, $\mathrm{pH}$ 7.4. In experiments in which we blocked impulse activity during growth, $1 \mu \mathrm{M}$ TTX was added to the medium when the nerve cords were plated (Arcaro and Lnenicka, 1995). All measurements of $\left[\mathrm{Ca}^{2+}\right]_{\mathrm{i}}$ were performed on cultures that were 2-3 d old.

High- $\mathrm{K}^{+}$depolarization and ionophore application. Motoneurons were depolarized with medium containing $60 \mathrm{~mm} \mathrm{~K}{ }^{+}$. Correct osmolarity was maintained by compensating for the increased $\mathrm{KCl}$ with an equal reduction in $\mathrm{NaCl}$. Recordings of resting membrane potentials from the motor giant, the largest of the phasic motor neurons, showed that the addition of $60 \mathrm{mM} \mathrm{K}^{+}$reduced the resting membrane potential from approximately -80 to $-30 \mathrm{mV}$ (Arcaro and Lnenicka, 1997). The $\mathrm{Ca}^{2+}$ ionophore 4-bromo-A23187 (Br-A23187) was prepared in DMSO at a concentration of $0.1 \mathrm{~mm}$. This solution was diluted (1:400) in normal medium to give a final Br-A23187 concentration of $0.25 \mu \mathrm{M}$ and was sonicated before application. To eliminate the effect of impulse activity on $\left[\mathrm{Ca}^{2+}\right]_{i}$, TTX was added initially during incubation in fura-2 AM (see below) and included in all perfusion solutions for both the high- $\mathrm{K}^{+}$and $\mathrm{Br}-\mathrm{A} 23187$ experiments. Solutions were exchanged by gravity flow perfusion at a rate of $3 \mathrm{ml} / \mathrm{min}$ for the chronic depolarization studies and $13 \mathrm{ml} / \mathrm{min}$ for the ionophore and brief depolarization studies (chamber volume, $<0.5 \mathrm{ml}$ ).

Measurement of $\left[\mathrm{Ca}^{2+}\right]_{i}$. Growing axons were loaded with fura-2 by incubating the cultures in medium containing $2 \mu \mathrm{M}$ fura- $2 \mathrm{AM}$ (Molecular Probes, Eugene, OR) for 50-60 min. Fura-2 AM (1 mM) in DMSO was added to culture medium at a 1:500 dilution. After loading with fura-2, growing axons were imaged with a $40 \times$ objective (Nikon Fluor; numerical aperture, 1.3) on an inverted microscope (Nikon Diaphot 200) equipped with an intensified CCD camera (VS-2525 intensifier and 200E CCD camera; Video Scope International, Herndon, VA). Fura-2 was excited by passing light from a $75 \mathrm{~W}$ xenon arc lamp through bandpass filters of $340 \pm 7$ or $380 \pm 8 \mathrm{~nm}$ (Chroma Technology, Brattleboro, VT). A Lambda-10 optical filter changer (Sutter Instrument Co., Novato, CA) was used to switch between excitation wavelengths. Typically, illumination intensity was attenuated with an ND4 filter. The excitation and emission wavelengths were separated with a $410 \mathrm{~nm}$ dichroic mirror, and emitted light was then passed through a $510 \pm 20 \mathrm{~nm}$ barrier filter. Metafluor software (Universal Imaging, West Chester, PA) was used for controlling the shutter, filter wheel, and image acquisition, as well as subsequent analysis.

The fura-2 fluorescence ratio (340:380) was used to estimate $\left[\mathrm{Ca}^{2+}\right]_{\mathrm{i}}$ using standard techniques (Grynkiewicz et al., 1985). Ratio pairs were acquired from 16 frame averages, and background values from a blank region of the slide were subsequently subtracted. We used $865 \mathrm{~nm}$ as the dissociation constant for fura-2 in crayfish axoplasm (Delaney et al., 1991; Mulkey and Zucker, 1992) and a viscosity correction factor of 0.7 (Poenie et al., 1986). As in previous studies of crayfish axons (Delaney et al., 1989), we measured ratios at zero $\mathrm{Ca}^{2+}\left(\mathrm{R}_{\min }\right)$ and saturating $\mathrm{Ca}^{2+}$ $\left(\mathrm{R}_{\max }\right)$ in vitro using solutions similar to crayfish cytoplasm (Wallin, 1967). Typical calibration values were $R_{\min }=0.32, R_{\max }=10.62$, and $\mathrm{F}_{0} / \mathrm{F}_{\mathrm{s}}=16.00$. Note that small errors in estimating the absolute $\mathrm{Ca}^{2+}$ concentrations should not affect the major findings of this study, which are based on relative $\mathrm{Ca}^{2+}$ concentrations.

In many types of cells (e.g., mammalian) fura- 2 is not a reliable indicator of $\mathrm{Ca}^{2+}$ concentrations higher than a couple of micromolar because of its high affinity for $\mathrm{Ca}^{2+}$ (Tsien, 1988). Fura-2 has a lower affinity for $\mathrm{Ca}^{2+}$ in crayfish neurons compared with mammalian cells $\left(K_{\mathrm{d}}, 865\right.$ vs $\left.220 \mathrm{nM}\right)$, and thus higher levels of $\mathrm{Ca}^{2+}$ can be measured. However, in some cases the $\mathrm{Ca}^{2+}$ concentrations in crayfish phasic axons were still higher than what could be reliably measured with fura-2. To eliminate these unreliable measurements, we did not use data in which the ratio exceeded $4\left(\mathrm{Ca}^{2+}\right.$ concentration of $\left.\sim 12 \mu \mathrm{M}\right)$.

The average $\mathrm{Ca}^{2+}$ concentration in neurites or growth cones was determined for individual neurons. These average values were used to determine the overall mean and for statistical analysis using a two-tailed Student's $t$ test. All values were mean \pm SE.

\section{RESULTS}

\section{$\left[\mathrm{Ca}^{2+}\right]_{\mathrm{i}}$ in growing phasic and tonic axons}

Growing neurites extend from the cut ends of the cultured phasic and tonic axons. Growth cones of phasic and tonic neurites advance at similar rates despite greater impulse activity in the tonic axons (Egid and Lnenicka, 1993; Arcaro and Lnenicka, 1997). Either tonic axons grow with higher $\left[\mathrm{Ca}^{2+}\right]_{i}$ than phasic axons, or the impulse activity does not produce elevations in $\left[\mathrm{Ca}^{2+}\right]_{\mathrm{i}}$ in the tonic neurites. This was examined by comparing $\left[\mathrm{Ca}^{2+}\right]_{\mathrm{i}}$ in growing phasic and tonic axons.

$\mathrm{Ca}^{2+}$ levels were measured during days $2-3$ of growth, which is a period when the neurites are generally elongating (Egid and Lnenicka, 1993). The $\left[\mathrm{Ca}^{2+}\right]_{\mathrm{i}}$ in tonic growth cones $(192 \pm 36$ nM; $n=17$ neurons; $n=31$ growth cones) and neurites (189 \pm 32 nм; $n=15$ neurons; $n=16$ neurites; $n=8$ animals) was significantly higher than in phasic growth cones $(110 \pm 11 \mathrm{nM} ; n=$ 16 neurons; $n=36$ growth cones; $p<0.05)$ and neurites $(111 \pm$ $18 \mathrm{nM} ; n=14$ neurons; $n=16$ neurites; $n=10$ animals; $p<0.05$ ). In some cases, we verified whether the growth cones were advancing at the time the $\mathrm{Ca}^{2+}$ measurements were performed. These results were similar to the previous ones; $\left[\mathrm{Ca}^{2+}\right]_{\mathrm{i}}$ was significantly higher in tonic growth cones $(163 \pm 31 \mathrm{~nm} ; n=9$ neurons; $n=12$ growth cones) than in phasic growth cones (90 \pm 14 nM; $n=9$ neurons; $n=14$ growth cones; $p<0.05)$. These results show that the active tonic axons normally grow with a higher $\left[\mathrm{Ca}^{2+}\right]_{\mathrm{i}}$ than the silent phasic axons.

\section{Depolarization produces a larger increase in $\left[\mathrm{Ca}^{2+}\right]_{\mathrm{i}}$ in growing phasic axons than in tonic ones}

When advancing phasic growth cones are depolarized with $60 \mathrm{~mm}$ $\mathrm{K}^{+}$for $40 \mathrm{~min}$, they are initially inhibited and often retract (Arcaro and Lnenicka, 1997). During this depolarization, most tonic growth cones continue to advance. To determine the role of intracellular $\mathrm{Ca}^{2+}$, the $\left[\mathrm{Ca}^{2+}\right]_{\mathrm{i}}$ was compared in growing phasic and tonic axons during depolarization.

Intracellular $\mathrm{Ca}^{2+}$ was measured in phasic and tonic growth cones during depolarization produced by $60 \mathrm{~mm} \mathrm{~K}^{+}$(Fig. 1, top). During the first $10 \mathrm{~min}$ of depolarization, $\left[\mathrm{Ca}^{2+}\right]_{\mathrm{i}}$ reached higher levels in phasic than in tonic growth cones (Fig. 2). Subsequently, $\left[\mathrm{Ca}^{2+}\right]_{\mathrm{i}}$ in phasic growth cones gradually increased, whereas $\left[\mathrm{Ca}^{2+}\right]_{\mathrm{i}}$ in the tonic growth cones decreased and plateaued at a lower level. The $\left[\mathrm{Ca}^{2+}\right]_{\mathrm{i}}$ in the neurites was similar to that in the growth cones during this period of depolarization. A number of growth cones and neurites were examined 40-60 min after the beginning of the depolarization. The $\left[\mathrm{Ca}^{2+}\right]_{\mathrm{i}}$ in phasic growth cones (4.61 $\pm 0.37 \mu \mathrm{M} ; n=37$ neurons; $n=70$ growth cones) and neurites (5.54 $\pm 0.33 \mu \mathrm{M} ; n=33$ neurons; $n=43$ neurites; $n=$ 16 animals) was significantly higher than in tonic growth cones $(1.38 \pm 0.21 \mu \mathrm{M} ; n=24$ neurons; $n=71$ growth cones; $p<$ $0.0001)$ and neurites $(1.56 \pm 0.33 \mu \mathrm{M} ; n=21$ neurons; $n=32$ neurites; $n=14$ animals; $p<0.0001)$.

Thus, the greater depolarization-induced inhibition and degeneration of growing phasic neurites compared with tonic neurites is correlated with higher $\left[\mathrm{Ca}^{2+}\right]_{i}$. The fact that $\left[\mathrm{Ca}^{2+}\right]_{\mathrm{i}}$ reaches higher levels in phasic axon growth suggests that the growing phasic axons have greater $\mathrm{Ca}^{2+}$ influx and/or a lower rate of $\mathrm{Ca}^{2+}$ removal than the growing tonic axons. 


\section{$60 \mathrm{mM} \mathrm{K}^{+}$}
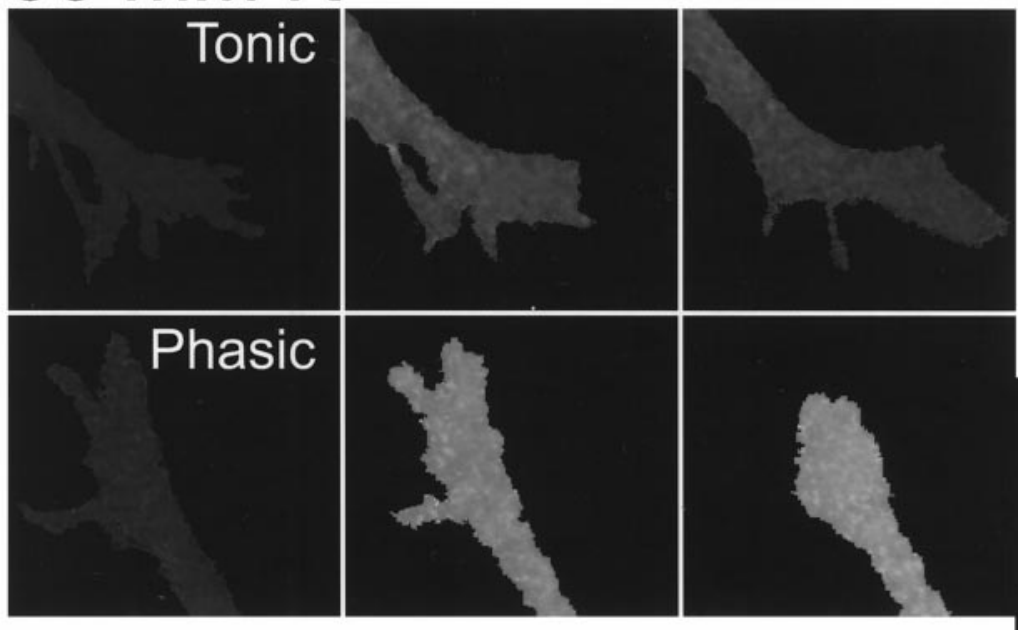

Figure 1. Ratio map of fura-2 fluorescence showing changes in $\left[\mathrm{Ca}^{2+}\right]_{\mathrm{i}}$ in neurites and growth cones during application of medium containing $60 \mathrm{mM} \mathrm{K}^{+}$or Br-A23187. Top, Medium containing $60 \mathrm{mM} \mathrm{K}^{+}$was applied to growing phasic and tonic axons. After $5 \mathrm{~min}$, $\left[\mathrm{Ca}^{2+}\right]_{\mathrm{i}}$ increased in both phasic and tonic growth cones, although the increase was greater in the phasic growth cone than the tonic one. Between 5 and $40 \mathrm{~min},\left[\mathrm{Ca}^{2+}\right]_{i}$ continued to rise in the phasic growth cone, whereas $\left[\mathrm{Ca}^{2+}\right]_{\mathrm{i}}$ decreased in the tonic growth cone. During this period of depolarization, the phasic growth cone clearly retracts, and the tonic growth cone continues to advance, although some of the finer processes are withdrawn. Bottom, Br-A23187 (0.25 $\mu \mathrm{M})$ was added to tonic axons grown with normal impulse activity (Tonic) and to tonic axons grown with no impulse activity (TTX-Tonic). After 5 min of Br-A23187 application, $\left[\mathrm{Ca}^{2+}\right]_{i}$ increased in both tonic and TTX-tonic growth cones. During 5-40 min, $\left[\mathrm{Ca}^{2+}\right]_{\mathrm{i}}$ continued to rise in the TTX-tonic growth cones; however, $\left[\mathrm{Ca}^{2+}\right]_{\mathrm{i}}$ decreased in the tonic growth cone. The TTX-tonic growth cone retracts and the tonic growth cone advances slightly. Thus, the previous history of impulse activity determines the ability of the growing axon to regulate intracellular $\mathrm{Ca}^{2+}$. The scale on the right shows the relationship between the ratio and the gray level.

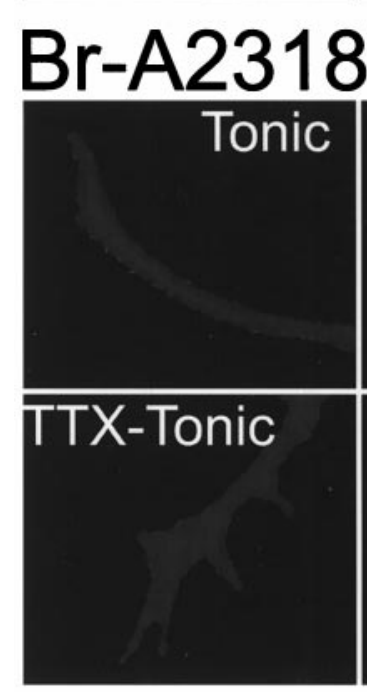

0

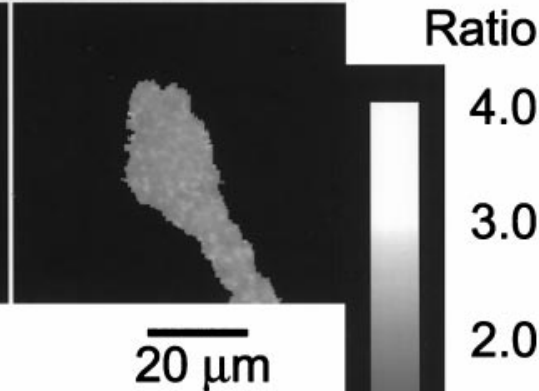

1.0

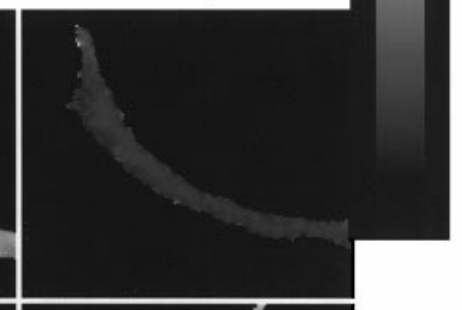

0.0

\section{$\mathrm{Ca}^{2+}$ levels go higher in growing phasic axons than tonic axons after addition of the $\mathrm{Ca}^{2+}$ ionophore $\mathrm{Br}-\mathrm{A} 23187$}

To determine whether the differences in $\mathrm{Ca}^{2+}$ regulation involved differences in $\mathrm{Ca}^{2+}$ removal, we measured $\left[\mathrm{Ca}^{2+}\right]_{\mathrm{i}}$ during perfusion of the $\mathrm{Ca}^{2+}$ ionophore $\mathrm{Br}-\mathrm{A} 23187$. Although $\mathrm{Br}-$ A23187 produced a rapid increase in $\left[\mathrm{Ca}^{2+}\right]_{i}$ in both phasic and tonic growth cones, the $\left[\mathrm{Ca}^{2+}\right]_{\mathrm{i}}$ reached higher levels in phasic growth cones. During the first 5 min of Br-A23187 application, $\left[\mathrm{Ca}^{2+}\right]_{\mathrm{i}}$ was three to four times greater in phasic growth cones than in tonic ones (Fig. 3). Subsequently, $\left[\mathrm{Ca}^{2+}\right]_{i}$ gradually increased and then plateaued in phasic growth cones, whereas $\left[\mathrm{Ca}^{2+}\right]_{\mathrm{i}}$ in tonic growth cones decreased before leveling off. After $40 \mathrm{~min}$ of ionophore application, $\left[\mathrm{Ca}^{2+}\right]_{\mathrm{i}}$ was approximately eight times greater in phasic growth cones than in tonic growth cones.

The remaining neurites and growth cones in the cultures were examined 40-60 min after the beginning of ionophore application. The $\left[\mathrm{Ca}^{2+}\right]_{\mathrm{i}}$ in phasic growth cones $(4.78 \pm 0.83 \mu \mathrm{M} ; n=18$ neurons; $n=35$ growth cones) and neurites (3.47 $\pm 1.02 \mu \mathrm{M} ; n=$ 12 neurons; $n=18$ neurites; $n=6$ animals) was significantly higher than in tonic growth cones $(1.28 \pm 0.31 \mu \mathrm{m} ; n=17$ neurons; $n=35$ growth cones; $p<0.001)$ and neurites $(0.91 \pm$ $0.16 \mu \mathrm{M} ; n=12$ neurons; $n=15$ neurites; $n=6$ animals; $p<$ $0.05)$. These results indicate that the growing phasic axons have a reduced capacity to regulate intracellular $\mathrm{Ca}^{2+}$ compared with tonic axons.

The differences in $\left[\mathrm{Ca}^{2+}\right]_{\mathrm{i}}$ for the growing phasic and tonic axons are likely to be underestimations during both depolarization and Br-A23187 application. In both experiments, some phasic axon data were omitted, because the $\left[\mathrm{Ca}^{2+}\right]_{\mathrm{i}}$ went too high to be reliably measured (see Materials and Methods), whereas none of the tonic axon data had to be omitted. In addition, some phasic growth had completely degenerated after 40 min of Br-A23187 treatment, and $\mathrm{Ca}^{2+}$ measurements could not be made during the 40-60 min period. Because the growth cones that degenerated likely had the highest $\left[\mathrm{Ca}^{2+}\right]_{\mathrm{i}}$, this explains why the measurements of $\left[\mathrm{Ca}^{2+}\right]_{\mathrm{i}}$ in phasic growth cones were higher during the first $40 \mathrm{~min}$ than during 40-60 $\mathrm{min}$.

\section{$\mathrm{Ca}^{2+}$ removal after brief depolarizing pulses}

To compare $\mathrm{Ca}^{2+}$ regulation in phasic and tonic growth cones further, we examined $\mathrm{Ca}^{2+}$ removal after brief depolarizing 


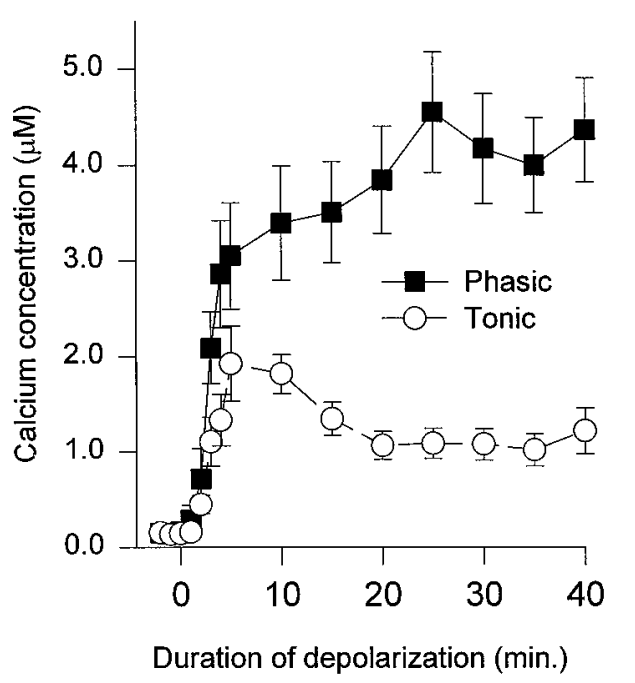

Figure 2. $\left[\mathrm{Ca}^{2+}\right]_{\mathrm{i}}$ in phasic and tonic growth cones as a function of time during depolarization with medium containing $60 \mathrm{mM} \mathrm{K}^{+}$. The $\left[\mathrm{Ca}^{2+}\right]_{\mathrm{i}}$ goes higher in phasic growth cones than in tonic growth cones. Mean values were obtained from 19 phasic growth cones from eight animals and 22 tonic growth cones from eight animals.

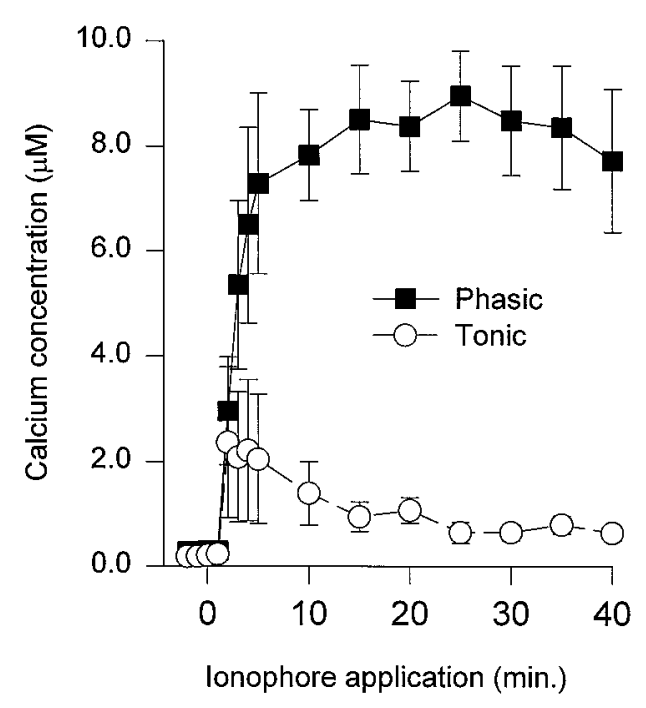

Figure 3. $\left[\mathrm{Ca}^{2+}\right]_{\mathrm{i}}$ in phasic and tonic growth cones plotted as a function of time during application of the $\mathrm{Ca}^{2+}$ ionophore $\mathrm{Br}-\mathrm{A} 23187(0.25 \mu \mathrm{M})$. After addition of $\mathrm{Br}-\mathrm{A} 23187,\left[\mathrm{Ca}^{2+}\right]_{\mathrm{i}}$ immediately goes higher in phasic growth cones than in tonic ones. The $\left[\mathrm{Ca}^{2+}\right]_{\mathrm{i}}$ remains extremely high in the phasic growth cones for the duration of the ionophore application. In tonic growth cones, $\left[\mathrm{Ca}^{2+}\right]_{\mathrm{i}}$ decreases after its initial increase. Mean values represent seven phasic growth cones from three animals and nine tonic growth cones from three animals.

pulses. The $\left[\mathrm{Ca}^{2+}\right]_{\mathrm{i}}$ was measured in neurites and growth cones during 60-90 sec depolarizing pulses $\left(60 \mathrm{mM} \mathrm{K}^{+}\right)$. At the end of the pulse, $\left[\mathrm{Ca}^{2+}\right]_{\mathrm{i}}$ declined more rapidly in tonic growth cones than in phasic ones (Fig. 4). Because the decline in $\left[\mathrm{Ca}^{2+}\right]_{\mathrm{i}}$ did not follow a single exponential, we measured the time required for $\left[\mathrm{Ca}^{2+}\right]_{\mathrm{i}}$ to decay to one-half of peak values. The time to one-half decay was significantly greater for phasic growth cones (167 $\pm 47 \mathrm{sec} ; n=7$ neurons; $n=17$ growth cones) than for tonic growth cones $(59 \pm 10 \mathrm{sec} ; n=5$ neurons; $n=14$ growth cones; $p<0.05)$. The differences in $\mathrm{Ca}^{2+}$ removal were not attributable to differences in the peak $\left[\mathrm{Ca}^{2+}\right]_{\mathrm{i}}$, because the peaks were similar in phasic $(3.90 \pm 0.83 \mu \mathrm{M})$ and tonic growth cones $(3.65 \pm 1.07$ $\mu \mathrm{M})$. In addition, even when the peak $\left[\mathrm{Ca}^{2+}\right]_{i}$ in phasic growth cones was lower, $\mathrm{Ca}^{2+}$ removal was still slow (Fig. 4, bottom right).

These differences in $\mathrm{Ca}^{2+}$ removal do not appear to result from differences in growth cone size or shape. That is, if $\mathrm{Ca}^{2+}$ removal results from extrusion of $\mathrm{Ca}^{2+}$ across the plasma membrane, the surface-to-volume ratio would be expected to influence the rate at which $\left[\mathrm{Ca}^{2+}\right]_{\mathrm{i}}$ declines. When $\mathrm{Ca}^{2+}$ removal was compared in phasic and tonic neurites, which generally have a uniform shape, we obtained results similar to those for growth cones (Fig. 4). $\mathrm{Ca}^{2+}$ levels took significantly longer to decay to one-half of peak values in phasic neurites $(216.5 \pm 58.9 \mathrm{sec} ; n=$ 5 neurons; $n=11$ neurites), which had a mean width of $7 \mu \mathrm{m}$ compared with tonic neurites $(60.5 \pm 19.4 \mathrm{sec} ; n=5$ neurons; $n=$ 14 neurites; $p<0.05$ ), which had a mean width of $5 \mu \mathrm{m}$. Similar differences were also seen when neurites of similar width were compared. Eliminating all phasic neurites $>7 \mu \mathrm{m}$ resulted in a mean width of $5 \mu \mathrm{m}$ and a time to one-half decay of $187.3 \pm 18.3$ sec ( $n=3$ neurons; $n=7$ neurites), which was also significantly greater than the tonic neurite values $(p<0.01)$. These results support faster $\mathrm{Ca}^{2+}$ removal by growing tonic axons compared with growing phasic axons.

\section{Differences in $\mathrm{Ca}^{2+}$ regulation are activity-dependent}

To determine whether the differences in $\mathrm{Ca}^{2+}$ regulation were activity-dependent, the impulse activity in the tonic axons was eliminated by adding $1 \mu \mathrm{M}$ TTX during their growth. After $2-3 \mathrm{~d}$ of growth in TTX, the $\mathrm{Ca}^{2+}$-handling capacity of these inactive tonic axons was examined by measuring changes in $\left[\mathrm{Ca}^{2+}\right]_{\mathrm{i}}$ after the addition of Br-A23187 (Fig. 1, bottom). These results were compared with the previous measurements obtained from tonic axons grown in normal medium. During $40 \mathrm{~min}$ of ionophore application, the inactive tonic growth cones showed weak $\mathrm{Ca}^{2+}$ regulation; $\left[\mathrm{Ca}^{2+}\right]_{\mathrm{i}}$ continued to increase during ionophore application (Fig. 5). These results were different from the control tonic axons and more similar to the normally inactive phasic axons. Similar differences between inactive and control tonic axons were also seen when $\left[\mathrm{Ca}^{2+}\right]_{i}$ was compared 40-60 min after the beginning of ionophore application. The $\left[\mathrm{Ca}^{2+}\right]_{i}$ in the inactive tonic growth cones $(3.15 \pm 0.60 \mu \mathrm{M} ; n=15$ neurons; $n=$ 37 growth cones) and neurites (2.96 $\pm 0.56 \mu \mathrm{M} ; n=14$ neurons; $n=21$ neurites) was significantly greater than in the control tonic growth cones $(1.28 \pm 0.31 \mu \mathrm{M} ; n=17$ neurons; $n=35$ growth cones; $p<0.01)$ and neurites $(0.91 \pm 0.16 \mu \mathrm{M} ; n=12$ neurons; $n=15$ neurites; $p<0.01)$. These results clearly show that axons growing with greater impulse activity develop greater $\mathrm{Ca}^{2+}$ handling capacity.

\section{DISCUSSION}

\section{Depolarization produced higher $\mathrm{Ca}^{2+}$ levels in the phasic axons and growth cones than in tonic ones}

During maintained depolarization with $60 \mathrm{mM} \mathrm{K}^{+},\left[\mathrm{Ca}^{2+}\right]_{\mathrm{i}}$ reaches higher levels in phasic neurites and growth cones than in tonic ones; $\left[\mathrm{Ca}^{2+}\right]_{\mathrm{i}}$ in phasic axon growth is three to four times greater than in tonic axon growth at the end of $40 \mathrm{~min}$ of depolarization. The $\left[\mathrm{Ca}^{2+}\right]_{\mathrm{i}}$ in phasic growth cones and axons during depolarization or ionophore application was very high and presumably was responsible for their retraction and eventual degeneration (Arcaro and Lnenicka, 1997). It is unclear what $\left[\mathrm{Ca}^{2+}\right]_{\mathrm{i}}$ is necessary to produce degeneration or the extent to which increases in $\left[\mathrm{Ca}^{2+}\right]_{\mathrm{i}}$ actually reflect the early stages of 


\section{Growth cones}

Figure 4. Changes in $\left[\mathrm{Ca}^{2+}\right]_{\mathrm{i}}$ in phasic and tonic growth cones and neurites produced by brief depolarizations. Pulses of $60 \mathrm{mM} \mathrm{K}^{+}$(bars) were applied to growing phasic and tonic axons in six animals, and changes in $\left[\mathrm{Ca}^{2+}\right]_{i}$ were measured. Top, Representative results for phasic and tonic growth cones. Phasic and tonic growth cones with similar peak $\left[\mathrm{Ca}^{2+}\right]_{\mathrm{i}}$ are compared. Bottom, Representative results from phasic and tonic neurites. Phasic and tonic neurites with similar widths and peak $\left[\mathrm{Ca}^{2+}\right]_{\mathrm{i}}$ are compared. On the left, the phasic and tonic neurites are 7 and $6 \mu \mathrm{m}$ wide, respectively. On the right, phasic and tonic neurites are 5 and $6 \mu \mathrm{m}$ wide, respectively. Note that at the end of the pulse, $\left[\mathrm{Ca}^{2+}\right]_{\mathrm{i}}$ consistently declined more rapidly in tonic growth cones and neurites than in phasic ones.

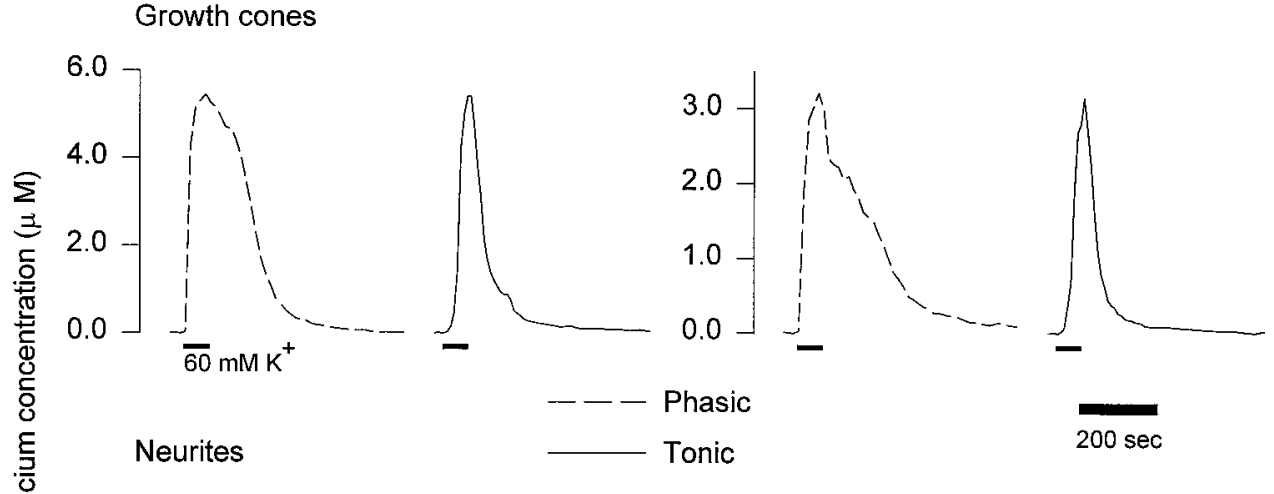

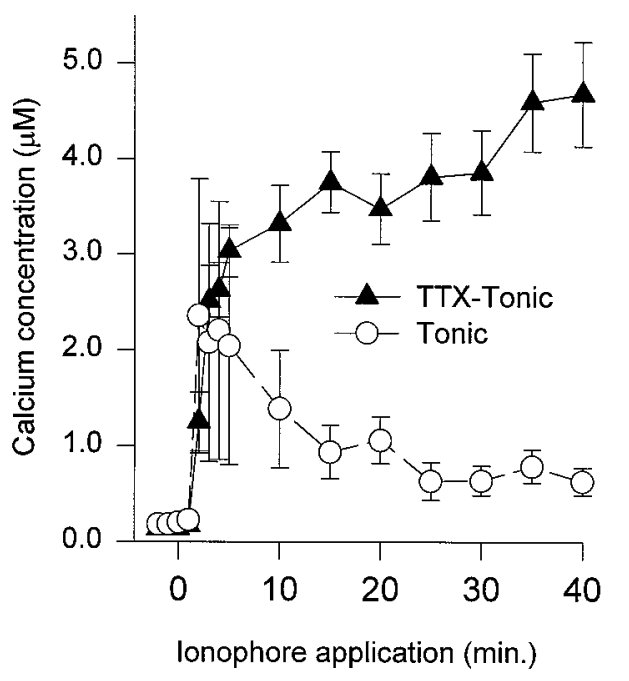

Figure 5. Differences in $\mathrm{Ca}^{2+}$ regulation for tonic axons grown with or without impulse activity. The $\mathrm{Ca}^{2+}$-handling capacity was compared in tonic axons grown in the presence of TTX with tonic axons grown in normal medium. The $\left[\mathrm{Ca}^{2+}\right]_{\mathrm{i}}$ was measured in inactive tonic growth cones during 40 min of Br-A23187 application. These values are compared with those obtained from tonic growth cones grown in normal medium (Fig. 3). Note that the $\left[\mathrm{Ca}^{2+}\right]_{\mathrm{i}}$ continued to increase in the inactive tonic growth cones in contrast to control tonic growth cones in which $\left[\mathrm{Ca}^{2+}\right]_{\mathrm{i}}$ declined after the initial increase.

degeneration. Very high levels of intracellular $\mathrm{Ca}^{2+}(>5 \mu \mathrm{M})$ appear to be required to trigger excitotoxic death of mouse cortical neurons (Hyrc et al., 1997). During depolarization of growing tonic axons, $\left[\mathrm{Ca}^{2+}\right]_{\mathrm{i}}$ stabilizes at values that are not high enough to trigger retraction or degeneration. In fact, although there is a loss of filopodia, growth cones usually continue to advance. Thus, the different responses of the growing phasic and tonic axons to depolarization involve differences in $\mathrm{Ca}^{2+}$ regulation.

There may also be differences in the sensitivity of phasic and tonic growth to $\mathrm{Ca}^{2+}$ because normally the $\left[\mathrm{Ca}^{2+}\right]_{\mathrm{i}}$ in the tonic growth cones is $\sim 70 \%$ greater than in phasic growth cones, although they advance at a similar rate (Arcaro and Lnenicka, 1997). The greater $\left[\mathrm{Ca}^{2+}\right]_{\mathrm{i}}$ in growing tonic axons apparently results from differences in impulse activity (Egid and Lnenicka, 1993), because the differences in $\left[\mathrm{Ca}^{2+}\right]_{\mathrm{i}}$ are not seen when TTX is added to the cultures before perfusing high- $\mathrm{K}^{+}$or $\mathrm{Br}-\mathrm{A} 23187$ solutions. Tonic growth cones may have a low sensitivity to intracellular $\mathrm{Ca}^{2+}$ because when depolarized they continue to advance, although the increase in $\left[\mathrm{Ca}^{2+}\right]_{\mathrm{i}}$ appears sufficient to inhibit growth cone advance in many other neurons (Cohan et al., 1987; Silver et al., 1989; Lankford and Letourneau, 1991; Fields et al., 1993). It appears that not all growth cones are equally sensitive to intracellular $\mathrm{Ca}^{2+}$; neurites from rat superior cervical ganglion neurons continue to elongate with elevated $\left[\mathrm{Ca}^{2+}\right]_{\mathrm{i}}$ (Garyantes and Regehr, 1992), and identified neurons in Helisoma show differences in their sensitivity to intracellular $\mathrm{Ca}^{2+}$ during growth (Torreano and Cohan, 1997). In fact, a prolonged increase in impulse activity can produce a reduction in the sensitivity of the growth cone to intracellular $\mathrm{Ca}^{2+}$ (Fields et al., 1993). Further studies are required to determine whether $\mathrm{Ca}^{2+}$ sensitivity is different in growing phasic and tonic axons.

\section{Tonic neurites and growth cones have a greater $\mathrm{Ca}^{2+}$ - handling capacity than phasic ones}

$\mathrm{Ca}^{2+}$ regulation was compared in phasic and tonic growth by adding the $\mathrm{Ca}^{2+}$ ionophore $\mathrm{Br}-\mathrm{A} 23187$ and monitoring changes in $\left[\mathrm{Ca}^{2+}\right]_{i}$. After Br-A23187 application, $\left[\mathrm{Ca}^{2+}\right]_{i}$ in phasic growth cones plateaued at levels four to five times greater than that observed in tonic growth cones. Thus, under conditions in which the density of $\mathrm{Ca}^{2+}$ influx was presumably similar, the resultant $\left[\mathrm{Ca}^{2+}\right]_{\mathrm{i}}$ is dramatically different. Of course this assumes that the ionophore is incorporated into growing phasic and tonic axons at equal densities, which seems likely. Further evidence for stronger $\mathrm{Ca}^{2+}$ regulation by tonic axon growth was provided by examining $\mathrm{Ca}^{2+}$ removal at the end of a brief depolarizing pulse. After a 60-90 sec depolarizing pulse, the $\left[\mathrm{Ca}^{2+}\right]_{\mathrm{i}}$ decreases more rapidly in tonic growth cones and neurites than in phasic ones. Thus, the differences in $\mathrm{Ca}^{2+}$ regulation include differences in $\mathrm{Ca}^{2+}$ removal; however, we do not know whether there are also differences in $\mathrm{Ca}^{2+}$ entry during depolarization.

The removal of intracellular free $\mathrm{Ca}^{2+}$ involves chelation by 
$\mathrm{Ca}^{2+}$-binding proteins, sequestration by intracellular organelles, and extrusion across the plasma membrane by the $\mathrm{Na}^{+}-\mathrm{Ca}^{2+}$ exchange and $\mathrm{Ca}^{2+}$ ATPase (for review, see Miller, 1991). Generally, $\mathrm{Ca}^{2+}$-binding proteins have a low capacity for buffering $\mathrm{Ca}^{2+}$; therefore, they probably contribute little to buffering the large $\mathrm{Ca}^{2+}$ loads imposed in these experiments. In addition, greater cytoplasmic buffering should slow the removal of $\mathrm{Ca}^{2+}$, whereas $\mathrm{Ca}^{2+}$ is removed more rapidly from tonic than phasic growth cones. Mitochondria are likely to be more effective than the endoplasmic reticulum at sequestering these large $\mathrm{Ca}^{2+}$ loads because of their greater capacity. Mitochondrial $\mathrm{Ca}^{2+}$ uptake can reduce the peak $\left[\mathrm{Ca}^{2+}\right]_{\mathrm{i}}$ during a depolarizing pulse and accelerate the initial decay of $\left[\mathrm{Ca}^{2+}\right]_{\mathrm{i}}$ at the end of the pulse; however, mitochondria then release $\mathrm{Ca}^{2+}$, which causes the $\left[\mathrm{Ca}^{2+}\right]_{\mathrm{i}}$ to plateau before returning to resting levels (Friel and Tsien, 1994; Werth and Thayer, 1994; Herrington et al., 1996). Again, because $\mathrm{Ca}^{2+}$ transients decay more rapidly in tonic growth cones than phasic ones, the greater $\mathrm{Ca}^{2+}$-handling capacity of tonic growth cones is unlikely to be attributable simply to greater mitochondrial $\mathrm{Ca}^{2+}$ uptake.

A higher rate of $\mathrm{Ca}^{2+}$ extrusion from growing tonic axons than from phasic ones could be responsible for their lower $\left[\mathrm{Ca}^{2+}\right]_{\mathrm{i}}$ during ionophore application and more rapid decay of $\left[\mathrm{Ca}^{2+}\right]_{i}$ at the end of depolarizing pulses. According to a model describing the dynamics of residual $\mathrm{Ca}^{2+}$ in crayfish motor terminals, an increase in the rate of $\mathrm{Ca}^{2+}$ extrusion will decrease the $\left[\mathrm{Ca}^{2+}\right]_{\mathrm{i}}$ plateau during a train of impulses and increase the rate of decay of $\left[\mathrm{Ca}^{2+}\right]_{i}$ at the end of the train (Tank et al., 1995). In crayfish motor terminals, the rate of $\mathrm{Ca}^{2+}$ extrusion appears to be a linear function of $\left[\mathrm{Ca}^{2+}\right]_{i}$ and can be modeled using a first-order Michaelis-Menten reaction (Tank et al., 1995). This formulation does not distinguish between the plasma membrane $\mathrm{Ca}^{2+}$ ATPase or $\mathrm{Na}^{+}-\mathrm{Ca}^{2+}$ exchange (Sala and HernandezCruz, 1990; Lagnado et al., 1992; Tank et al., 1995). Based primarily on studies of squid axons, the $\mathrm{Na}^{+}-\mathrm{Ca}^{2+}$ exchange has been classified as having a low affinity but high capacity for $\mathrm{Ca}^{2+}$ transport, whereas the $\mathrm{Ca}^{2+}$ ATPase has a high affinity but low capacity (Baker and DiPolo, 1984).

It appears reasonable that the plasma membrane $\mathrm{Na}^{+}-\mathrm{Ca}^{2+}$ exchanger could play a major role in $\mathrm{Ca}^{2+}$ extrusion during the large $\mathrm{Ca}^{2+}$ loads imposed in our experiments. The $\mathrm{Na}^{+}-\mathrm{Ca}^{2+}$ exchanger was important in removing intracellular $\mathrm{Ca}^{2+}$ from Helisoma neurons during a large $\mathrm{Ca}^{2+}$ load produced by $\mathrm{Br}$ A23187 (Mills and Kater, 1990). There is evidence that $\mathrm{Na}^{+}-$ $\mathrm{Ca}^{2+}$ exchange extrudes $\mathrm{Ca}^{2+}$ from rat brain synaptosomes (Sanchez-Armass and Blaustein, 1987), and based on immunocytochemistry the $\mathrm{Na}^{+}-\mathrm{Ca}^{2+}$ exchanger is concentrated at presynaptic terminals, as well as in growing neurites and growth cones (Luther et al., 1992). $\mathrm{Na}^{+}-\mathrm{Ca}^{2+}$ exchange, as well as mitochondrial $\mathrm{Ca}^{2+}$ uptake, play a role in removing cytoplasmic free $\mathrm{Ca}^{2+}$ from crayfish motor terminals (Mulkey and Zucker, 1992; Tang and Zucker, 1997). Differences in $\mathrm{Na}^{+}-\mathrm{Ca}^{2+}$ exchange in growing phasic and tonic axons could result from differences in the exchanger and/or their ability to extrude $\mathrm{Na}^{+}$(Blaustein, 1988).

\section{Differences in $\mathbf{C a}^{2+}$ regulation are activity-dependent}

The strong $\mathrm{Ca}^{2+}$ regulation seen in tonic axons appears to result from its high-impulse activity levels during growth. Tonic axons growing in TTX showed weaker $\mathrm{Ca}^{2+}$ regulation than control ones during the application of $\mathrm{Br}-\mathrm{A} 23187$. The strong $\mathrm{Ca}^{2+}$ regulation produced by high-impulse activity persists for at least $1 \mathrm{hr}$, and probably much longer, because impulse activity in the tonic axons was blocked for $>1 \mathrm{hr}$ before examining their $\mathrm{Ca}^{2+}$ handling (see Materials and Methods).

The activity-dependent strengthening of $\mathrm{Ca}^{2+}$ regulation could involve changes in protein synthesis. For example, the synthesis of $\mathrm{Ca}^{2+}$-binding proteins can be upregulated by increased electrical activity (Lowenstein et al., 1991). In addition, there are activity-dependent differences in the density and activity of mitochondria in crayfish motor axons and terminals (Lnenicka et al., 1986, 1997; Nguyen and Atwood, 1994). Mitochondrial changes could play a role in modulating $\mathrm{Ca}^{2+}$ regulation, if not through direct $\mathrm{Ca}^{2+}$ uptake, then indirectly through the production of ATP.

\section{Relevance to neuronal physiology}

Because $\left[\mathrm{Ca}^{2+}\right]_{i}$ is so important to neuronal function, the activity-dependent development of $\mathrm{Ca}^{2+}$ regulation could affect a number of neuronal properties. For the developing axon, $\mathrm{Ca}^{2+}$ regulation can affect how impulse activity and environmental cues shape the pattern of growth. In the adult, greater $\mathrm{Ca}^{2+}$. handling capacity could make neurons more resistant to $\mathrm{Ca}^{2+}$ neurotoxicity produced by insults such as excitotoxicity (Choi, 1988). Activity-dependent differences in $\mathrm{Ca}^{2+}$ regulation could influence cell excitability, e.g., intracellular $\mathrm{Ca}^{2+}$ levels influence the firing properties of lobster neurons (Turrigiano et al., 1994).

Activity-dependent differences in $\mathrm{Ca}^{2+}$ regulation at motor terminals are likely to influence transmitter release. For example, $\mathrm{Ca}^{2+}$ removal is likely to influence the production of post-tetanic potentiation (PTP), because PTP requires the buildup of residual $\mathrm{Ca}^{2+}$ (Delaney et al., 1989; Delaney and Tank, 1994). Because chronic in vivo stimulation of crayfish phasic motor terminals reduces their capacity to produce PTP (Pahapill et al., 1986), it may be that increased impulse activity strengthens $\mathrm{Ca}^{2+}$ regulation in mature motor terminals, as well as in growing axons.

\section{REFERENCES}

Arcaro KF, Lnenicka GA (1995) Intrinsic differences in axonal growth from crayfish fast and slow motoneurons. Dev Biol 168:272-283.

Arcaro KF, Lnenicka GA (1997) Differential effects of depolarization on the growth of crayfish tonic and phasic motor axons in culture. J Neurobiol 33:85-97.

Baker PF, DiPolo R (1984) Axonal calcium and magnesium homeostasis. Curr Top Membr Transp 22:95-147.

Blaustein MP (1988) Calcium transport and buffering in neurons. Trends Neurosci 11:438-443.

Choi DW (1988) Calcium-mediated neurotoxicity: relationship to specific channel types and role in ischemic damage. Trends Neurosci 11:465-469.

Cohan CS, Connor JA, Kater SB (1987) Electrically and chemically mediated increases in intracellular calcium in neuronal growth cones. J Neurosci 7:3588-3599.

Delaney KR, Tank DW (1994) A quantitative measurement of the dependence of short-term synaptic enhancement on presynaptic residual calcium. J Neurosci 14:5885-5902.

Delaney KR, Zucker RS, Tank DW (1989) Calcium in motor nerve terminals associated with post-tetanic potentiation. J Neurosci 9:3558-3567.

Delaney K, Tank DW, Zucker RS (1991) Presynaptic calcium and serotonin-mediated enhancement of transmitter release at crayfish neuromuscular junction. J Neurosci 11:2631-2643.

Egid K, Lnenicka GA (1993) Regeneration from crayfish phasic and tonic motor axons in vitro. J Neurobiol 24:1111-1120.

Fields RD, Guthrie PB, Russell JT, Kater SB, Malhotra BS, Nelson PG (1993) Accommodation of mouse DRG growth cones to electrically induced collapse: kinetic analysis of calcium transients and set-point theory. J Neurobiol 24:1080-1098.

Friel DD, Tsien RW (1994) An FCCP-sensitive $\mathrm{Ca}^{2+}$ store in bullfrog sympathetic neurons and its participation in stimulus-envoked changes in $\left[\mathrm{Ca}^{2+}\right]_{\mathrm{i}}$. J Neurosci 14:4007-4024. 
Garyantes TK, Regehr WG (1992) Electrical activity increases growth cone calcium but fails to inhibit neurite outgrowth from rat sympathetic neurons. J Neurosci 12:96-103.

Grynkiewicz G, Poenie M, Tsien RY (1985) A new generation of $\mathrm{Ca}^{2+}$ indicators with greatly improved fluorescence properties. J Biol Chem 260:3440-3450.

Herrington J, Park YB, Babcock DF, Hille B (1996) Dominant role of mitochondria in clearance of large $\mathrm{Ca}^{2+}$ loads from rat adrenal chromaffin cells. Neuron 16:219-228.

Hong SJ, Lnenicka GA (1995) Activity-dependent reduction in voltagedependent calcium current in a crayfish motoneuron. J Neurosci 15:3539-3547.

Hong SJ, Lnenicka GA (1997) Characterization of a P-type calcium current in a crayfish motoneuron and its selective modulation by impulse activity. J Neurophysiol 77:76-85.

Hyrc K, Handran SD, Rothman SM, Goldberg MP (1997) Ionized intracellular calcium concentration predicts excitotoxic neuronal death: observations with low-affinity fluorescent calcium indicators. J Neurosci 17:6669-6677.

Kater SB, Mills LR (1991) Regulation of growth cone behavior by calcium. J Neurosci 11:891-899.

Katz B (1969) The release of neural transmitter substances. Springfield, IL: Thomas.

Lagnado L, Cervetto L, McNaughton PA (1992) Calcium homeostasis in the outer segment of retinal rods from the tiger salamander. J Physiol (Lond) 455:111-142.

Lankford KL, Letourneau PC (1991) Roles of actin filaments and three second-messenger systems in short-term regulation of chick dorsal root ganglion neurite outgrowth. Cell Motil Cytoskeleton 20:7-29.

Lnenicka GA, Atwood HL, Marin L (1986) Morphological transformation of synaptic terminals of a phasic motoneuron by long-term tonic stimulation. J Neurosci 6:2252-2258.

Lnenicka GA, Case CJ, Travis JL (1997) Activity-dependent differences in the mitochondrial density of crayfish phasic and tonic motor axons. J Exp Zool 280:18-27.

Lowenstein DH, Miles MF, Hatam F, McCabe T (1991) Upregulation of calbindin-D28K mRNA in the rat hippocampus following focal stimulation of the perforant path. Neuron 6:627-633.

Lukas W, Jones KA (1994) Cortical neurons containing calretinin are selectively resistant to calcium overload and excitotoxicity in vitro. Neuroscience 61:307-316.

Luther PW, Yip RK, Bloch RJ, Ambesi A, Lindenmayer GE, Blaustein MP (1992) Presynaptic localization of sodium/calcium exchangers in neuromuscular preparations. J Neurosci 12:4898-4904.

Mattson MP, Rychlik B, Chu C, Christakos S (1991) Evidence for calcium-reducing and excitoprotective roles for the calcium-binding protein calbindin-D28K in cultured hippocampal neurons. Neuron 6:41-51.

Miller RJ (1991) The control of neuronal calcium homeostasis. Prog Neurobiol 37:255-285.

Mills LR, Kater SB (1990) Neuron-specific and state-specific differences in calcium homeostasis regulate the generation and degeneration of neuronal architecture. Neuron 2:149-163.

Morgan JI, Curran T (1991) Stimulus-transcription coupling in the nervous system: involvement of the inducible proto-oncogenes fos and jun. Annu Rev Neurosci 14:421-452.

Mulkey RM, Zucker RS (1992) Post-tetanic potentiation at the crayfish neuromuscular junction is dependent on both intracellular calcium and sodium ion accumulation. J Neurosci 12:4327-4336.

Nguyen PV, Atwood HL (1994) Altered impulse activity modifies synaptic physiology and mitochondria in crayfish phasic motor neurons. J Neurophysiol 72:2944-2955.

Nishi R, Berg DK (1981) Effects of high $\mathrm{K}^{+}$concentrations on the growth and development of ciliary ganglion neurons in cell culture. Dev Biol 87:301-307.

Pahapill PA, Lnenicka GA, Atwood HL (1986) Neuronal experience modifies synaptic long-term facilitation. Can J Physiol Pharmacol 64:1052-1054.

Poenie M, Alderton J, Steinhardt R, Tsien R (1986) Calcium rises abruptly and briefly throughout the cell at the onset of anaphase. Science 33:886-889.

Porter NM, Thibault O, Thibault V, Chen K-C, Landfield PW (1997) Calcium channel density and hippocampal cell death with age in long-term culture. Neuroscience 17:5629-5639.

Sala F, Hernandez-Cruz A (1990) Calcium diffusion modeling in a spherical neuron, relevance of buffering properties. Biophys $\mathrm{J}$ $57: 313-324$.

Sanchez-Armass S, Blaustein MP (1987) Role of sodium-calcium exchange in regulation of intracellular calcium in nerve terminals. Am J Physiol 252:C595-C603.

Silver RA, Lamb AG, Bolsover SR (1989) Elevated cytosolic calcium in the growth cone inhibits neurite elongation in neuroblastoma cells: correlation of behavioral states with cytosolic calcium concentration. J Neurosci 9:4007-4020.

Tang Y, Zucker RS (1997) Mitochondrial involvement in post-tetanic potentiation of synaptic transmission. Neuron 18:483-491.

Tank DW, Regehr WG, Delaney KR (1995) A quantitative analysis of presynaptic calcium dynamics that contribute to short-term enhancement. J Neurosci 15:7940-7952.

Torreano PJ, Cohan CS (1997) Electrically induced changes in $\mathrm{Ca}^{2+}$ in Helisoma neurons: regional and neuron-specific differences and implications for neurite outgrowth. J Neurobiol 32:150-162.

Tsien RY (1988) Fluorescence measurement and photochemical manipulation of cytosolic free calcium. Trends Neurosci 11:419-424.

Turrigiano G, Abbott LF, Marder E (1994) Activity-dependent changes in the intrinsic properties of cultured neurons. Science 264:974-977.

Wallin BG (1967) Intracellular ion concentrations in single crayfish axons. Acta Physiol Scand 70:419-430.

Werth JL, Thayer SA (1994) Mitochondria buffer physiological calcium loads in cultured rat dorsal root ganglion neurons. J Neurosci 14: $348-356$. 